\title{
Editorial
}

\section{Consolidando o legado de uma longa trajetória}

Com a publicação deste fascículo 48 do volume 21, iniciamos um movimento reflexivo sobre a trajetória da Paidéia, que nos estimula a pensar em nosso próprio percurso, de certo modo imbricado na história deste periódico, primeiro como membro do Conselho Editorial, de fevereiro de 1998 a julho de 2007 e, posteriormente, como Editor, desde agosto de 2007.

A função de Editor de uma revista científica impõe desafios consideráveis, porém, ao mesmo tempo, oferece uma rica oportunidade de ampliarmos as fronteiras de nossa atuação profissional, abrindo frentes de diálogo e canais de comunicação com autores, consultores, membros da Comissão e do Conselho Editorial, bibliotecários, funcionários dos órgãos de fomento à pesquisa e às publicações, técnicos das bases indexadoras, secretárias, diagramador, webdesigner, entre outros profissionais, sem contar os bolsistas e estagiários. Além dos problemas de natureza científica, há inúmeros afazeres na área técnico-administrativa.

Uma das razões para compartilhamos com a comunidade científica nosso júbilo com os frutos colhidos no percurso trilhado desde que assumimos a função de Editor da Paidéia, há cerca de quatro anos, é que a revista está às vésperas de completar seus 20 anos de vida, o que ocorrerá em agosto próximo. Como todo ponto de inflexão, esse é um momento que nos convida à reflexão.

Duas décadas de vida e trabalho. Aproveitemos dessa efeméride tão significativa para situarmos a trajetória evolutiva da revista, de modo que possamos nos munir de insumos para traçar seus rumos daqui para frente. Nesse sentido, temos a convicção de que estamos contribuindo para consolidar o legado de uma longa trajetória, que se iniciou em agosto de 1991 com a iniciativa de um grupo de docentes do então Departamento de Psicologia e Educação da Faculdade de Filosofia, Ciências e Letras de Ribeirão Preto da Universidade de São Paulo (FFCLRP-USP). A Profa. Lisete Diniz Ribas Casagrande e o Prof. José Marcelino de Rezende Pinto foram os primeiros editores e, nessa condição pioneira, cuidaram de gerir os passos iniciais da revista, que nasceu como Paidéia: Cadernos de Educação.

A partir do segundo número, lançado em fevereiro de 1992 , a Profa. Zélia Maria Mendes Biasoli Alves assumiu a função de Editora, incorporando-se à dupla de Editores formada pela Profa. Lisete e pelo Prof. José Marcelino. Dessa função ela jamais se afastaria. Desde então, e até sua morte prematura, em 2007, a Profa. Zélia foi a espinha dorsal da Paidéia. Foram 15 anos de dedicação, tenacidade, luta, investimento e abnegação. Seu empreendedorismo e sua paixão pela produção do conhecimento jamais serão esquecidos. Ao olhar para trás, resgatamos imagens que ficaram submersas na memória, como a de uma mulher de alma guerreira e visionária, que marcou nossas vidas com seu sorriso fácil, sua inteligência e sua inquietude. Sem dúvida, ela tem um lugar assegurado na lembrança de todos aqueles que tiveram o privilégio de testemunhar sua energia invejável e seu espírito de liderança à frente de tantos projetos que contribuíram para impulsionar o crescimento não apenas da Paidéia, como de nossa instituição.

Atualmente, temos a satisfação de contar com um grupo de trabalho altamente qualificado e competente, com quem dividimos as múltiplas tarefas que o funcionamento de uma revista exige. Os membros da Comissão Editorial coordenam o processo de tramitação dos manuscritos submetidos e têm a delicada missão de intermediar a comunicação entre autores e assessores ad hoc.

Paralelamente às transformações do projeto gráfico da revista, implementadas a partir do fascículo 42 do volume 19, de janeiro-abril de 2009, temos investido de forma consistente na ampliação das bases indexadoras. A partir deste fascículo, obtivemos a indexação na base Pascal, do Institut de l'Information Scientifique et Technique (INIST) da França. Outras solicitações de indexação encontram-se em andamento e aguardamos para breve uma resposta positiva. Nesta época em que as revistas investem maciçamente para conquistar relevância internacional, devemos nos concentrar nas condições estruturais que podem alicerçar essa desejada mudança de patamar.

Desse modo, esperamos que o crescimento científico da Paidéia se consolide cada vez mais, ampliando seu merecido reconhecimento nacional e internacional. Neste fascículo, a seção destinada aos artigos é aberta com o estudo de autoria de Ana Alayde Werba Saldanha, Isabel Cristina Vasconcelos de Oliveira e Regina Ligia Wanderlei de Azevedo, da Universidade Federal da Paraíba, intitulado $O$ autoconceito de adolescentes escolares. As autoras comparam o autoconceito de 686 adolescentes escolares, associado às variáveis sexo, faixa etária e tipo de escola frequentada (pública ou privada), por meio do Inventário dos Esquemas de Gênero do Autoconceito. Os resultados indicam que os adolescentes apresentaram autoconceito positivo, variando em função do sexo (maior para o feminino), idade (quanto menor a idade, maior a percepção negativa masculina e a feminina) e tipo de escola (autoconceito mais positivo na escola pública). Esses resultados fornecem subsídios para a elaboração de estratégias mais condizentes com as necessidades dos adolescentes, seja no âmbito familiar, escolar ou social.

A segunda contribuição, de autoria de Anna Elisa de Villemor-Amaral e Maria Aparecida dos Santos Machado, 
da Universidade São Francisco, intitulada Indicadores de depressão do Zulliger no Sistema Compreensivo (ZSC), objetiva verificar se os indicadores de depressão que compõem a Constelação de Depressão (DEPI) do Rorschach no Sistema Compreensivo (SC) auxiliam no diagnóstico de depressão por meio do Zulliger SC, em uma amostra de 27 pacientes com depressão e 27 não-pacientes, do sexo feminino. Foram aplicados os instrumentos: SCID-I, questionário de identificação e Zulliger. As autoras concluíram que o ZSC é um instrumento que pode contribuir no diagnóstico da depressão.

Na sequência, o artigo Avaliação cognitiva psicométrica e assistida de crianças com baixa visão moderada, de Ana Cristina Barros da Cunha, da Universidade Federal do Rio de Janeiro e Sônia Regina Fiorim Enumo e Cláudia Patrocínio Pedroza Canal, da Universidade Federal do Espírito Santo, analisa o desempenho de 12 crianças, com idade entre cinco e nove anos, com baixa visão moderada, em provas assistidas (Jogo de Perguntas de Busca para Crianças com Deficiência Visual - PBFG-DV ou Children Analogical Thinking Modifiability CATM) e um instrumento psicométrico (Escala de Maturidade Mental Columbia-EMMC). As provas se mostraram sensíveis para avaliar e diferenciar as crianças que apresentaram baixa classificação na escala de inteligência, mostrando seu potencial de aprendizagem. Porém, as autoras, discutem a adequação do CATM para avaliar a população com necessidades especiais.

Também avaliando crianças, 28 participantes na faixa etária de quatro a seis anos, o próximo artigo Atribuição de estados mentais e compreensão conversacional: estudo com pré-escolares, de autoria de Maria Regina Maluf e Eliana Cristina Gallo-Penna, da Pontifícia Universidade Católica de São Paulo e Maria José dos Santos, da Universidade Federal de Goiás, investiga as relações entre compreensão conversacional e a atribuição de estados mentais. A coleta de dados foi feita por meio da aplicação individual de tarefas de compreensão conversacional e de teoria da mente. Os resultados mostraram efeito da idade a favor das crianças mais velhas, para as duas variáveis, bem como uma correlação positiva entre elas.

Dando continuidade às pesquisas na área de avaliação do desenvolvimento infantil, a próxima contribuição é intitulada Análise de instrumentos para triagem do desenvolvimento infantil, de autoria de Ana Regina Lucato Sigolo e Ana Lúcia Rossito Aiello, da Universidade Federal de São Carlos. As autoras compararam o Denver II e a EDC com uma escala de referência (EEDP) quanto à identificação de crianças com atraso de desenvolvimento, verificando diferença nos resultados. Participaram 24 bebês de cinco a 11 meses, de ambos os sexos, frequentadores de creches municipais. Os resultados indicam que a escala EDC e o Denver II não podem ser considerados semelhantes à escala EEDP. Quanto ao gênero, não houve diferença significativa. Também não houve convergência de itens falhos segundo as áreas. As autoras reforçam a importância de se ter cautela na escolha de instrumentos para triagem e a necessidade de obter informações sobre o desenvolvimento da criança procedentes de diferentes fontes.
A próxima contribuição, Práticas educativas parentais e repertório comportamental infantil: comparando crianças diferenciadas pelo comportamento, de Alessandra Turini Bolsoni-Silva, da Universidade Estadual Paulista e Sonia Regina Loureiro, da Universidade de São Paulo, objetiva comparar práticas educativas parentais e comportamentos infantis de um grupo de 27 crianças, considerado clínico/com problema de comportamento, com 26 crianças, que constituíram o grupo não-clínico/sem problema de comportamento. $\mathrm{O}$ critério de inclusão das crianças nos grupos clínico e não-clínico foi obtido a partir do CBCL, e os dados da interação pais-filhos foram colhidos por meio do Roteiro de Entrevista de Habilidades Sociais Educativas Parentais (RE-HSE-P). Os resultados apontam que os comportamentos que diferenciam os grupos clínico e não-clínico são, sobretudo, os relacionados às práticas educativas positivas e às habilidades sociais infantis.

A contribuição seguinte, Paciente laringectomizado total: perspectivas para a ação clínica do psicólogo, de Leopoldo Nelson Fernandes Barbosa, da Universidade Federal de Pernambuco e Ana Lúcia Francisco, da Universidade Católica de Pernambuco, investiga, por meio de um enfoque qualitativo, as repercussões psicossociais na construção da subjetividade de pacientes laringectomizados e de seus cuidadores. Os autores notaram que o adoecimento é vivido como um momento de crise, no qual predomina sentimentos de desamparo e desalojamento. A perda da fala pode levar o paciente a isolar-se socialmente, provocando intensa angústia e sofrimento. Os cuidadores sofrem diante da possibilidade da perda de um ente querido e, também, por tentativas, nem sempre exitosas, de prover apoio para as novas necessidades que se apresentam após o adoecimento. Tais dados podem, segundo os autores, fornecer subsídios valiosos para a ação clínica do psicólogo.

Na sequência, o artigo $O$ apoio da rede social a transexuais femininas, de Milene Soares, Marianne Ramos Feijó, Nelson Iguimar Valério, Carmem Lúcia dos Santos Maia Siquieri e Maria Jaqueline Coelho Pinto, da Faculdade de Medicina de São José do Rio Preto, aborda uma questão atual e relevante: a relação de transexuais femininas com suas redes sociais. Participaram cinco pacientes submetidas à cirurgia de transgenitalização, que responderam à entrevista semi-estruturada e a perguntas para a construção de genogramas e mapas de rede. As entrevistadas relataram situações em que se sentiram apoiadas, inclusive diante da decisão de operar, mas também descreveram situações nas quais vivenciaram sentimentos de humilhação e exclusão pelo fato de expressarem e viverem sua sexualidade de forma diferente da maioria das pessoas. O estudo mostrou que ainda prevalece a posição heteronormativa, que alimenta preconceitos e, frequentemente, favorece atos de discriminação direcionados às mulheres transexuais.

$\mathrm{O}$ artigo Grupo de orientação de mães no contexto de uma clínica-escola, de autoria de Maria Benedita Lima Pardo e Margarida Maria Silveira Britto de Carvalho, da Universidade Federal de Sergipe, descreve as características de funcionamento de um grupo de orientação para mães de crianças em 
fila de espera para atendimento psicoterápico. Os dados foram coletados por meio de entrevistas iniciais e finais e no decorrer dos encontros. Procedeu-se à análise de conteúdo das informações relacionadas às falas das mães e aos procedimentos de intervenção. Os resultados indicaram aumento nos diálogos com os filhos, preocupação em dedicar-lhes mais tempo e a entender seus pontos de vista, busca em estabelecer limites, envolvendo também outras pessoas da família. As autoras concluem que, após o atendimento das mães, as mudanças relatadas por elas revelam que houve alterações positivas no funcionamento do microssistema familiar.

O próximo artigo, Um estudo de follow up em psicoterapia psicanalítica de casais, de Maria Galrão Rios e Isabel Cristina Gomes, da Universidade de São Paulo, oferece uma reflexão sobre a manutenção das mudanças psíquicas ocorridas na psicoterapia psicanalítica com casais ao longo do tempo. Com base no método de estudo de caso, fundamentado no referencial psicanalítico, analisaram dois casos clínicos que estiveram em processo terapêutico, respectivamente, por três anos e por dois anos e meio, sendo realizadas duas sessões de acompanhamento após o término da psicoterapia. As autoras concluem que esse tipo de intervenção mostrou-se efetiva para a elucidação de conflitos conjugais latentes e também para a promoção de um ambiente familiar saudável e favorecedor do desenvolvimento emocional dos filhos.

De cunho teórico, o artigo De Freud a Deleuze: os descaminhos da resistência, de autoria de Fernanda Canavêz e Regina Herzog, da Universidade Federal do Rio de Janeiro, problematiza o lugar marginal que a resistência pode vir a ocupar no campo psicanalítico, tomada como o que deve ser superado para a pretensa boa continuidade do processo de análise. Ao contrário desta perspectiva, indagam se a resistência não poderia ser entendida como um espaço de produção subjetiva. As autoras lançam mão de noções do campo da filosofia, percorrendo algumas considerações de Deleuze a respeito do tema, para reconhecer na resistência não apenas um movimento de mero revide ao trabalho de investigação psicanalítica, mas uma afirmação que abre a possibilidade efetiva de criação.

Também de natureza teórica, e revendo conceitos freudianos, o artigo Sigmund Freud, da psicoprofilaxia à educação psicanaliticamente esclarecida: um percurso, de Gleisson Roberto Schmidt, da Universidade Federal de Santa Catarina, descreve e analisa os pressupostos e as contribuições de Freud no campo da educação a partir de suas elaborações acerca da sexualidade infantil e da organização pulsional. Enfatiza que Freud abandona, ao longo de sua obra, o ideal de uma educação psicoprofilática, não obstante mantenha sempre presente a esperança de uma "outra educação", menos repressora e mais sublimadora.

Encerrando a seção de artigos, a última contribuição, intitulada Educação e infância em alguns escritos de Walter Benjamin, de Anita Helena Schlesener, da Universidade Federal do Paraná, traz uma reflexão teórica educação infantil. A autora aborda alguns escritos de Walter Benjamin sobre educação e infância, expressos também na obra Infância em Berlim por volta de 1900. O artigo acentua a originalidade desse autor que, no contexto da sociedade europeia de 1920, problematizou questões relevantes sobre educação e sugeriu novos paradigmas de interpretação.

Por fim, a última seção da revista apresenta a resenha Prevenção de erros no ensino da leitura, de Geraldina Porto Witter, da Universidade Camilo Castelo Branco. A autora apresenta o livro Preventing misguided reading: new strategies for guided reading teacher, de Jan Burkins e Melody Croft, considerada uma obra útil para auxiliar professores a transformarem as crianças em leitores proficientes.

Este número se encerra com as Normas de Publicação. Na confluência de tantas contribuições de alto padrão científico, este fascículo da Paidéia espelha a impressionante versatilidade e vigor da Psicologia e Educação brasileiras. Ao constituírem um painel colorido e multifacetado, os artigos nos oferecem uma leitura instigante, com a qual as contribuições ganham solidez e densidade, enriquecendo o cenário das publicações na área de Psicologia e Educação.

Desejamos uma boa leitura a todos.

Manoel Antônio dos Santos Editor 